\title{
EL CRISTO DE LA CLEMENCIA: ITINERARIOS DE UNA IMAGEN EXCEPCIONAL
}

\author{
THE CHRIST OF CLEMENCY: \\ ITINERARIES OF AN EXCEPCIONAL IMAGE
}

\author{
Rafael de Besa Gutiérrez \\ debesag@hotmail.com
}

\begin{abstract}
A pesar de la extensa bibliografía que existe en torno al Cristo de la Clemencia de Juan Martínez Montañés, siempre ha existido cierta confusión en torno a los espacios en los que ha estado almacenado o expuesto, desde su llegada al monasterio de la Cartuja hasta su depósito en la sacristía de los Cálices de la catedral de Sevilla. En el presente estudio se ofrece una secuencia cronológica que abarca las distintas situaciones que obligaron a movilizar a la imagen, ofreciendo información en torno a los distintos espacios que ha ocupado a lo largo del siglo XIX.

Palabras clave: Juan Martínez Montañés; Cristo de la Clemencia; catedral de Sevilla; Museo de Bellas Artes de Sevilla; siglo XIX.

In spite of the extensive bibliography that exists about the Christ of Clemency by Juan Martínez Montañés, there has always been some confusion about the places in which it has been exposed or deposited from his arrival to the Carthusian Monastery until his deposit in the Chalices's Sacristy at the Cathedral of Seville. This paper offer a chronological sequence that includes the different situations that forced to move the image, offering information about the different spaces that it has occupied along the 19th century.

Keywords: Juan Martínez Montañés; Christ of Clemency; Cathedral of Seville; Museum of Fine Arts of Seville; $19^{\text {th }}$ century.
\end{abstract}




\section{INTRODUCCIÓN: DONACIÓN A LA CARTUJA}

El Cristo de la Clemencia fue encargado a Juan Martínez Montañés por el arcediano de Carmona, Mateo Vázquez de Leca en $1603^{1}$, siendo donado posteriormente al monasterio de Santa María de las Cuevas el 24 de septiembre de 1614 "con expresa condición de que jamás se sacase ni enajenase del convento"2, circunstancia que, como se verá a continuación, quedó muy lejos de ser cumplida (Figura 1). Una vez llegó a la Cartuja, estuvo en primer lugar en la capilla del Nacimiento o de San Bruno, pasando en 1616 a instalarse en la capilla de Santa Ana, en la que podía tener culto público ${ }^{3}$.

La movilización del Crucificado llegó con la invasión francesa a principios del siglo XIX. A pesar de los intentos por proteger la Cartuja, era lógico que debido a su gran extensión terminase convirtiéndose en fortaleza y almacén para los franceses. Debido al interés de los invasores en conservar todas las riquezas patrimoniales posibles, se ordenó el traslado de estas a las dependencias del Alcázar en un proceso que duró catorce días, iniciándose el 15 de abril de 1811 y extendiéndose hasta el 30 del mismo mes, dedicando algunos días de este periodo a la acomodación de los bienes ${ }^{4}$. Lógicamente, la obra de Montañés, junto al resto de grandes obras artísticas, estuvo custodiada en el Alcázar durante la amenaza invasora, la cual duró hasta 1812, momento en el que, a pesar de las limitaciones económicas, se inició un proceso de devolución del patrimonio allí atesorado.

El primer envío de piezas a la Cartuja se efectuó el 17 de julio de 1813, aunque no sería hasta una segunda remesa fechada el 13 de octubre en la que podemos localizar al Crucificado dentro del listado de obras devueltas: "Una efixe de Cristo Crusificado, su autor Montañez"5.

${ }^{1}$ HERNÁNDEZ DÍAZ, José: Juan Martínez Montañés (1568-1649). Sevilla, 1987, p. 111.

${ }^{2}$ HAZAÑAS Y LA RUA, Joaquín: Vázquez de Leca 1573-1649. Sevilla, 1918, p. 101.

${ }^{3}$ FERNÁNDEZ ROJAS, Matilde: Patrimonio artístico de los conventos masculinos desamortizados en Sevilla durante el siglo XIX: Trinitarios, Franciscanos, Mercedarios, Jerónimos, Cartujos, Mínimos, Obregones, Menores y Filipenses. Sevilla, 2009, p. 408.

${ }^{4}$ RAMOS SUÁREZ, Manuel Antonio: "El monasterio de la Cartuja de Sevilla. Ocupación Napoleónica y vuelta al orden”, Archivo Hispalense, 256-257, 2001, p. 219.

5 Archivo General del Palacio Real, copia microfilmada del Archivo del Real Alcázar de Sevilla, caja 600, exp. 32, "Relación de pinturas que se encontraban en los Reales Alcázares y fueron devueltas al monasterio de la Cartuja tras la ocupación napoleónica"; consultado en RAMOS SUÁREZ, M. A.: "El monasterio de la Cartuja de Sevilla...”, op. cit., p. 240. 


\section{LA DESAMORTIZACIÓN DE MENDIZÁBAL}

De esta forma podemos ubicar al Cristo de la Clemencia de nuevo en su capilla de la Cartuja, en la que permanecería hasta la llegada de la desamortización de Mendizábal en 1835. Los distintos decretos desamortizadores implicaron una serie de problemas a los que tuvieron que hacer frente de la forma más eficaz posible, ya que estaba en juego la integridad del patrimonio de la ciudad. Tras conocerse la supresión de monasterios y casas religiosas, el gobierno autorizó la creación de comisiones provinciales supervisadas por las academias de bellas artes, destinadas a "examinar, inventariar y recoger cuanto contengan los archivos y bibliotecas de los monasterios y conventos suprimidos, y las pinturas, objetos de escultura u otros que deban conservarse", trabajos que se hicieron oficiales a través de la real orden de 29 de julio de $1835^{6}$. Las obras de arte recogidas conformarían la base del Museo Provincial, cuya creación vino autorizada con la real orden de 16 de septiembre de 1835, así como la elección de un edificio que resultase adecuado para tal empresa.

Tras el nombramiento de la "Comisión Recolectora" para Sevilla y su provincia, se decidió que los trabajos debían empezarse por "los Conventos extramuros en que con mayor facilidad podrían temerse maliciosas extracciones"7. De esta forma, el equipo destinado a atender la Cartuja, San Jerónimo de Buenavista y San Isidoro del Campo fue el compuesto por José Bécquer, Juan Felipe Quiroga, Juan de Astorga y Manuel de Zayas. Debido a que en esta primera junta no se llegaron a concretar todos los medios con los que disponían para enfrentarse a la recolección de obras, se instó a continuar la sesión el 23 de octubre de 1835 . En aquella reunión se volvió a hacer hincapié en la necesidad de adoptar medidas más eficaces para evitar los numerosos robos que estaban sufriendo durante todo este proceso. Tras ello se pasó a tratar el otro gran problema con el que se encontraban, el de carecer aún de un edificio para el museo y teniendo que recurrir a depósitos o almacenes: "Se determinó que los respectivos Comisionados pasasen a la Cartuja y Capuchinos, y clasificando los Efectos que debían destinarse al Museo, los depositasen en Havitacion conveniente y los dejaran encargados a la custodia de las personas à cuyo cargo estuviesen los referidos Edificios"s.

El encontrar un local adecuado para el almacenamiento de las obras fue el gran problema que se desarrolló de forma paralela a la recolección en sí misma. Desde un principio se barajaron varias sedes para el Museo, siendo el convento de San Pablo el que gozaba de mayor interés por parte de los comisionados. Sin embargo, López Cepero compartió con el resto de la junta las dificultades con las

\footnotetext{
${ }^{6}$ Gaceta de Madrid, $\mathrm{n}^{\circ}$ 217, 4-8-1835.

7 Archivo de la Comisión de Monumentos de Sevilla (A.C.M.S.), Libro de actas I, 9-10-1835.

8 Ibidem, 23-10-1835.
} 
que se estaba encontrando en la petición de este edificio ${ }^{9}$, sugiriendo como alternativa el uso del hospital del Espíritu Santo que estaba a la espera de ser desocupado por una disposición del gobierno.

Se tiene constancia de que entrado el año 1836, a pesar de no haberse encontrado un local para el museo, las tareas de recolección de obras siguieron desarrollándose gracias al uso de un depósito o almacén. Tenemos conocimiento de que en el mes de marzo ya estaba en funcionamiento un lugar de almacenamiento para las piezas desamortizadas puesto que, en la junta del 7 de marzo de 1836, "se encargó á los Comisionados que antes habían hecho los Ynventarios de Cartuja se personasen con el Comisionado de Amortizacion para formalizar los Ynventarios" $"$. Si ya en este momento se puede intuir el funcionamiento de un almacén como base de operaciones, sería en la junta del 17 de marzo cuando nos encontramos con la confirmación de su existencia: "El Domingo á las 12 se realizará la operación de marcar los Cuadros que nuevamente hayan entrado en el Depósito y no lo estuvieran, y se rectificaran los inventarios de los recogidos" 11.

De esta forma sabemos que el monasterio de la Cartuja fue uno de los primeros edificios en ser intervenidos y que, entrado el mes de marzo de 1836, sus obras principales debían estar custodiadas en un almacén a la espera de ser inventariadas correctamente. Por lo tanto, ¿dónde se encontraba exactamente en este momento el Cristo de Montañés?

Siguiendo la crónica del proceso, se vuelve a incidir en la existencia de un almacén varias veces, pero solo en una ocasión se lo nombra como el "almacén de la calle Colcheros"12. Al localizar la calle en el plano de Olavide de 1771 (Figura 2) puede verse que coincide con la actual calle Tetuán, lugar en el que se encontraba el hospital del Espíritu Santo, edificio que se cita anteriormente como una hipotética sede alternativa en caso de que no se llegase a conseguir San Pablo. De ahí que podamos decir con certeza que se consiguiese el Hospital del Espíritu Santo - $\mathrm{o}$ alguna de sus dependencias- $\mathrm{y}$ fuese empleado como depósito de obras recogidas, mientras que la comisión siguiese a la espera de la obtención de San Pablo como sede para el futuro Museo.

Por lo tanto, podemos concluir que, durante este primer trimestre de 1836, es muy posible que el Cristo de la Clemencia se localizase almacenado en el depósito de la calle Colcheros, aunque no se puede descartar la existencia de algún otro almacén del que no tenemos noticias, algo probable debido al importante número de obras recogidas.

\footnotetext{
${ }^{9}$ Ibid., 30-10-1835.

${ }_{10}$ Ibid., 7-3-1836.

${ }^{11}$ Ibid., 17-3-1836.

12 Ibid., 11-7-1836.
} 
Finalmente, y tras meses de insistencias y negociaciones, se acordó la toma de posesión del convento de San Pablo el 12 de abril de $1836^{13}$. En principio consideraban este espacio como el que se destinaría a futuro Museo Provincial, función que como veremos a continuación, terminó limitándose a la de almacenamiento. Prácticamente, a la semana de tomarse San Pablo, comenzaron los trabajos de traslado de obras, lo que lleva a pensar que durante la primavera de 1836 cabe la posibilidad que pasase a depositarse en el convento de San Pablo la imagen del Cristo de la Clemencia.

Meses más tarde, recibió López Cepero la real orden de 20 de junio de 1836, mediante la cual se destinaba el convento de San Pablo al establecimiento de las oficinas de Hacienda, ofreciéndose a cambio cualquier otro edificio para la instalación del Museo.

A pesar de la real orden, la comisión siguió utilizando con normalidad el edificio como lugar de reuniones y habilitando sus salas para el almacenamiento de las obras desamortizadas, no iniciándose hasta el mes de octubre de 1836 las negociaciones para tratar de suspender las oficinas de Hacienda que ya existían en el convento ${ }^{14}$.

\section{TRASLADO A LA CATEDRAL POR LA AMENAZA DE LA GUERRA CARLISTA}

Sin embargo, llegó el invierno de aquel 1836 y Sevilla se encontró envuelta en plena agitación debido a la guerra carlista. La presencia amenazante de la expedición del general Gómez amedrentó al personal de la comisión tras la toma de Córdoba en el mes de octubre ${ }^{15}$. En aquel momento, las obras recogidas estaban distribuidas entre el hospital del Espíritu Santo y San Pablo, la sede provisional del museo.

"Cuando Gómez entró en Ecija y Sevilla temió ser ocupada por el mismo, el Alcalde Const'. Dn. Fco. de Paula Mendez pasó oficio a Cepero fecho en 7 de Octubre de 36, diciéndole qe evacuase de cuadros en el momento al dicho hospital, destinado a los heridos $\mathrm{q}^{\mathrm{e}}$ resultasen de la defensa de la ciudad; $\mathrm{y}$ a las once de la noche, esto es, tres horas después de recibida la notificación del alcalde, un comisario de guerra se presentó a recoger las llaves de los almacenes para poner en la calle todo lo q e contenían" ${ }^{\prime \prime}$.

13 A.C.M.S., Libro de actas I, 11-4-1836.

14 Ibid., 10-9-1836.

15 RAMÍREZ OLID, José Manuel: "La primera guerra carlista en osuna. La expedición del general Gómez", Cuadernos de los Amigos de los Museos de Osuna, 15, 2013, pp. 20-27.

16 PABÓN, Jesús: "Del Deán López Cepero: Apunte autógrafo y autobiográfico", Boletín de la Real Academia de la Historia, T. CLXXI, nº III, 1974, p. 473. 
La llegada del general Gómez a la provincia de Sevilla le fue notificada inmediatamente a López Cepero junto a la orden expresa del alcalde de retirar de forma urgente todo el patrimonio del hospital del Espíritu Santo de cara a la posibilidad de tener que acoger a los posibles heridos que resultasen del hipotético enfrentamiento. El problema principal es que junto a la orden no se le ofreció ningún espacio o local en el que depositar las piezas que existían en el hospital. De forma paralela quedaba además descartada la posibilidad del traslado a San Pablo, debido a que acababa de instalarse en él un batallón.

Añadir la problemática de que los coleccionistas extranjeros acechaban a la espera de encontrarse con un caos similar al de la invasión francesa que les resultase favorecedor para la adquisición de obras de maestros sevillanos de forma despiadada, con especial atención en las obras de Murillo.

Ante aquella situación tan crítica solicitó unas horas más hasta el día siguiente, garantizando a cambio la evacuación de las obras. Uno de los factores determinantes para salvar aquellas obras fue el que en ese momento desempeñase Cepero el cargo de mayordomo de la catedral, lugar perfecto adonde trasladar las piezas desde el hospital del Espíritu Santo. Además, aquel cargo le permitió aprovechar al personal de la misma, organizando cuadrillas a las que se unieron vecinos, gracias a los que finalmente se consiguió el objetivo: "El día amaneció enmedio de un conflicto general en $\mathrm{q}^{\mathrm{e}}$ solo la actividad y constancia de un hombre de hierro hubiera podido llevar a cabo la traslación de los cuadros a los almacenes de la Iglesia, empleando hasta carros de la basura y otros medios de difícil referencia" 17 .

En este momento es cuando el Cristo de la Clemencia debió de llegar por primera vez a atesorarse en el que sería su emplazamiento definitivo en el futuro: "y a fuerza de ruegos y reflecciones pudo alcanzar del Comisario $q^{\mathrm{e}}$ esperase hasta las doce de la mañana siguiente a cuya hora tendría trasladados los [cuadros], algunos muy grandes y pesados $\mathrm{q}^{\mathrm{e}}$ se guardaban en el Hospital, sin contar otras muchas cosas, $\mathrm{q}^{\mathrm{e}}$ no siendo cuadros eran sí muy dignas de conservarse para el mundo de las artes y de las letras" 18 .

Tras la marcha del general Gómez con sus tropas hacia el norte, la ciudad de Sevilla fue volviendo a la normalidad de forma progresiva y mirando a López Cepero como una figura crucial en la salvaguarda del patrimonio de la ciudad durante la amenaza de guerra.

En la siguiente Junta del Museo, se trató el problema que había quedado tras la amenaza de contienda: los batallones instalados en San Pablo. Aquello representaba una tremenda amenaza para el patrimonio allí atesorado, ya fuese por la mera presencia o porque desembocase en otro apresurado traslado de obras siguiendo el ejemplo del caso de hacia escasos meses.

\footnotetext{
17 Ibidem.

18 Ibid., p. 473.
} 
"El Sr. Marques de Arco hermoso que los efectos que tenia almacenados en S. Pablo estaban espuestos por las circunstancias de invasión enemiga de que se veia amenazada la Ciudad, á ser desalojados con precipitación, por que fuese necesario el otro edificio para las fortificaciones de la Ciudad, o bien para alojar tropa como ya en la actualidad la había. La Comision tomo en consideración este punto interesantisimo, y acordo que se trasladasen los efectos mas preciosos al Colegio de S. Miguel. Sin embargo de dejar reunido lo menos interesante en el Refectorio de S. Pablo para no perder la posesion del edificio, interin S.M. resuelve del destino qe ha de darse á este edificio. Nombro al Sr. Cepero para qe pasase a ver al Sr Dean de la Sta Iglesia sobre este particular"19.

De esta forma decidieron trasladar las piezas más valiosas al colegio de San $\mathrm{Miguel}^{20}$, dejando las menos interesantes en el refectorio del convento de San Pablo como pretexto para no perder la titularidad del edificio mientras se resolvía por el gobierno su destino. La junta aprovechó el cargo de mayordomo de López Cepero para encargarle a él la tarea de ponerse en contacto con el deán de la catedral.

La combinación del terror a la guerra y la desidia de los miembros de la Junta del Museo frente a cualquier tema patrimonial hizo que recayese toda la responsabilidad sobre López Cepero. De ahí que decidiese disolver la Junta tras no haber encontrado apoyo alguno en la anterior amenaza de contienda: "En ninguno de estos actos intervino la autoridad, y menos la Junta del Museo, que quedó reducida a mí solo, y solo yo, me atrevo a decirlo a la faz del mundo, hubiera podido en aquellas circunstancias llevar a cabo empresa tan difícil y arriesgada, para cuyo desempeño nadie me proveyó de medios, ni de auxilios, más que en los que por razón de mi oficio tenía a mi disposición de la Fábrica de la Iglesia, pero el amor a las artes y a la Patria me suministró la suficiente actividad y diligencia para que todo se pusiera a salvo, y aún en último caso de la invasión, se hallasen en sitio seguro" 21 .

Manuel López Cepero cumplió eficazmente el encargo de ponerse en contacto con el cabildo, al que le manifestó "el peligro grave que corrían muchos monumentos Históricos y Artísticos esparcidos en varios conventos, cuyos edificios estaban destinados, algunos a cuarteles y otros condenados a la demolición"22. De esta forma consiguió la autorización para el depósito en la catedral de obras

19 A.C.M.S., Libro de actas I, 2-12-1836.

${ }^{20}$ La elección del colegio de San Miguel era la más idónea de cara a una futura aceptación del traslado de piezas a la catedral, ya que este se encontraba justo enfrente.

${ }^{21}$ MERCHÁN CANTISÁN, Regla: El Deán López-Cepero y su colección pictórica. Sevilla, 1979, p. 50.

${ }^{22}$ Archivo de la Catedral de Sevilla (A.C.S.), Actas Capitulares de 1837, ff. 1lv-12v, cita consultada en PALOMERO PÁRAMO, Jesús: "La Colección escultórica: los fondos góticos, renacentistas barrocos", en Obras Maestras del Museo de Bellas Artes de Sevilla. Siglos XV-XVIII (pequeño y mediano formato). Sevilla, 1992, p. 49. 
que estaban en San Pablo y en el cercano colegio de San Miguel, repartiéndolas "por la Sacristía Mayor, Sacristía de los Cálices y capillas de San José, San Antonio y San Francisco"23.

Años después, en la crónica sevillana de Amador de los Ríos de 1844 se aplaudió el trabajo de Cepero a la vez que se incidió en un detalle curioso, el de la reacción de los viajeros al ver las importantes obras del Museo inmersas en la catedral de Sevilla, de entre las cuales con seguridad destacaría el Crucificado de Montañés: "aquel honrado sacerdote, que era á la sazón mayordomo de fábrica de la santa y patriarcal iglesia, les ofreció un asilo respetable en la catedral de Sevilla, cuyos muros enriquecieron por algún tiempo. Allí los doctos viageros, que vienen á este suelo de encantos para gozar sus bellezas, contemplaban, alumbradas por la luz vacilante y misteriosa de las góticas vidrieras, las inmortales creaciones del gran pintor de Andalucía: allí sobrecogida el alma á vista de tantos prodigios, bajo tan grandiosas bóvedas, se olvidaba de la feroz tormenta, que en torno de aquel sagrado recinto bramaba desencadenada, y allí en fin, acudían á beber inspiraciones los artistas, cuyas pacíficas glorias son hijas del retiro"24.

\section{EN EL MUSEO DE BELLAS ARTES DE SEVILLA}

Llegado el año 1837 se creó una nueva comisión científico-artística responsable del Museo a la que se permitió la elección de un local nuevo ${ }^{25}$. Mientras tanto, el convento de San Pablo siguió funcionando como almacén debido a que los trabajos de recogida volvieron a desarrollarse. Se llegó al punto de que se excedieron sus posibilidades de almacenaje tras la recolección de los cuadros del colegio de Santo Tomás, teniendo que volver a recurrirse al depósito de piezas en la catedral.

Sería el 7 de octubre de 1837 cuando en junta, decidió la comisión proponer el antiguo convento de la Merced como el ideal para desarrollar en él el futuro Museo Provincial. El proceso para obtenerlo se extendió a lo largo del año 1838, durante el cual se tiene constancia del movimiento de obras de arte a San Pablo con cuadrillas dirigidas por Cabral Bejarano. Aproximadamente un año fue el tiempo que se tardó en habilitar el local, quedando establecido oficialmente el Museo actual por primera vez en el mes de octubre de 1839 gracias a los trabajos que llevaron a cabo el marqués de Arco Hermoso y Cabral Bejarano.

Una vez iniciado el funcionamiento de la institución, aún quedaba pendiente la recogida de un gran número de obras depositadas en otros espacios, como era el caso del Crucificado de Montañés, que se encontraba en la catedral junto a otras importantes esculturas. Queda como testimonio de ello un listado de esculturas

${ }^{23}$ PALOMERO PÁRAMO, J.: “La Colección escultórica...”, op. cit., p. 49.

${ }^{24}$ AMADOR DE LOS RÍOS, José: Sevilla pintoresca o Descripción de sus más célebres monumentos artísticos. Sevilla, 1844, p. 355.

${ }^{25}$ Real Decreto de 27-4-1837. 
incluido dentro de un inventario firmado por Cabral Bejarano el 31 de diciembre de 1840 (Figura 3) ${ }^{26}$. Entre ellas no solo encontramos al Cristo de la Clemencia, sino otras obras del mismo autor, las magistrales piezas de Torrigiano o las Virtudes de Juan de Solís.

El proceso para el traslado de las piezas de la catedral al Museo se inició tras oficiar el jefe superior político al cabildo el 28 de julio de 1841 solicitándole que se entregase a Cabral Bejarano "los efectos artísticos depositados en la Santa Iglesia" 27 , petición aceptada en la sesión capitular del día siguiente. El proceso se extendió hasta pasada la primavera del año $1842^{28}$ debido al importante número de obras que se encontraban depositadas en la catedral, siendo principalmente las de gran tamaño, caso de la Inmaculada Colosal de Murillo o el Martirio de San Andrés de Roelas. En el caso de las esculturas, no tardaron tanto en instalarse en el antiguo convento de la Merced, ya que tenemos noticias de su presencia en el Museo en la Sevilla Artística de Juan Colón y Colón, obra terminada de redactar en octubre de $1841^{29}$.

En esta obra pionera en su género, Colón realizó un estudio de los principales monumentos a destacar de Sevilla, coincidiendo con los primeros años en los que el Museo aún estaba siendo montado. La crónica de la visita al edificio resulta enormemente interesante, ya que ofrece un testimonio en primera persona de cómo el escritor se encontró con el caos que imperaba en los primeros años de creación.

Colón empieza nombrando cómo tras la desamortización pasaron las riquezas a ser custodiadas en aquel edificio para formar lo que sería la colección pública artística de la ciudad de Sevilla. Resulta que, a ojos del pueblo, todo lo que rodeaba al Museo era un misterio en el que solo se era consciente de lo que se hacía de puertas para adentro. En la visita del cronista trató de conseguir información sobre lo que se gestaba, a lo que solo recibió negativas: "Hace años que se está en la formación del Museo i todavía al presente carece Sevilla de un tesoro público propio de su provincia. Parece que el misterio envuelve á este establecimiento, pues nosotros al tratar de sacar algunos apuntes sobre lo que aparece en la actualidad, no hemos podido hacerlo, por hallarnos con obstáculos i prohibiciones: sin duda porque en España es delito hacer un bien al pais. ¡Triste fatalidad!”.

${ }^{26}$ Archivo de la Real Academia de Bellas Artes de Santa Isabel de Hungría, Antecedentes del Museo Provincial de Pinturas y Esculturas de Sevilla. Existe una copia de este inventario en el Archivo del Museo de Bellas Artes de Sevilla.

27 A.C.S., Autos Capitulares 1841, f. 77v. Consultado en PALOMERO PÁRAMO, J.: "La Colección escultórica...", op. cit., p. 49.

28 A.C.S., Autos Capitulares 1842, ff. 73v-74. Consultado en PALOMERO PÁRAMO, J.: "La Colección escultórica...", op. cit., p. 50.

${ }^{29}$ COLÓN Y COLÓN, Juan: Sevilla Artística. Sevilla, 1841, pp. 141-145. 
Tras enumerar las pinturas que vio y las condiciones en que se encontraban pasó a tratar las esculturas, mucho más limitadas en cuanto a cantidad, pero de una calidad abrumadora: "El santo Domingo desnudo de medio cuerpo, i en acto de penitencia, es una de las producciones de Juan Martinez Montañez, su autor, en donde hizo ostentación de su saber i de la gran intelijencia que poseía en el arte: demostró mayores conocimientos en el famoso crucifijo, que fué del monasterio de Cartuja i que hizo en el año de 1614 ; en su jénero es una de las primeras obras que se conserva en Europa de la escultura moderna: hai otras estátuas de este autor".

Al año siguiente, en 1842, publicaron los editores del periódico El Sevillano una especie de guía que seguía el mismo formato empleado por Colón. En ella también relatan la visita al Museo, el cual se encontraba en aquel momento cerrado debido a las numerosas obras que se estaban realizando en el edificio. La presencia del Crucificado queda reflejada en el siguiente párrafo: "También ecsisten en este establecimiento escelentes esculturas entre ellas la magnífica estátua de barro cocido de Pedro Torrijiano, que representa á san Gerónimo; el santo Domingo de Juan Martínez Montañez y el ponderado crucifijo que hizo en el año de 1614; las cuatro virtudes, de Solís, discípulo de aquel autor, y otras obras de mérito no tan sobresaliente" 30 .

La Sevilla pintoresca de Amador de los Ríos se publicó en 1844, convirtiéndose en todo un referente en el estudio de los monumentos de la ciudad. Concebida inicialmente como una continuación de la obra de Colón, ésta resultaría ampliada enormemente, siendo de gran importancia el apartado dedicado al Museo Provincial. Una vez asimilado el estudio que ofrece Amador de los Ríos, puede establecerse una evolución que parte de las obras citadas anteriormente y ofrece una visión de cómo evolucionaron los trabajos en el Museo en aquel periodo de dos o tres años.

La crónica sobre el Museo viene precedida de una extensa reflexión en torno a la escuela sevillana de la pintura y de su evolución a lo largo de los años anteriores, así como de las influencias o presencia de artistas extranjeros: "Ya hemos tenido ocasión de mencionar antes de ahora á Juan Martínez Montañez, cuyas producciones han merecido los elogios de los hombres entendidos en artes. El Museo tiene también algunas obras de este escultor, que nació en Alcalá la Real á fines del siglo XVI y fué discípulo del granadino Pablo de Rojas. Las dos estatuas que mas han llamado nuestra atención son un santo Domingo penitente que perteneció al convento de Portaceli y un Crucifijo que donó á la Cartuja en 1614 don

${ }^{30}$ Noticia histórica de los principales monumentos artísticos de Sevilla formada por los editores de El Sevillano. Sevilla, 1842, pp. 31-32. 
Matías Vazquez de Leca. En estas obras mostró Montañez que unía al tálento la instrucción y el estudio necesarios para ser un artista excelente" 31.

Como puede comprobarse a través del testimonio de estas guías, el protagonismo del Cristo de la Clemencia de Martínez Montañés fue enorme dentro de una colección casi exclusivamente pictórica, algo que lo convirtió con total seguridad en uno de los principales atractivos del Museo en estos primeros años de funcionamiento. Debido a las dificultades para exhibirlo por sus grandes dimensiones, estuvo colocado él solo en una pequeña sala anexa al salón principal -antigua iglesia del convento-. Desde ese momento y durante décadas sería conocido aquél espacio como el "cuarto del Cristo".

\section{TRASLADO DEFINITIVO A LA CATEDRAL DE SEVILLA}

Acerca de las razones que llevaron al traslado de la talla del Museo a la catedral de Sevilla, la tradición ha apuntado a que fue producto de una orden dada por la reina Isabel II. Tras la revisión de la documentación se consigue esclarecer el origen del interés por trasladar la célebre talla.

La propuesta llega de parte de Manuel López Cepero, vicepresidente de la Comisión de Monumentos en este momento, que solicita poner una comunicación al ministro de gobernación para trasladar el Crucificado de Montañés a la catedral el 5 de marzo de 1845, justificando aquella decisión en "que solo en aquel Templo era donde podía lucir su merito y no en el Museo por carecer de un sitio tan a propósito como el que allí tenia; á mas de que la veneración que en Sevilla se le tributa hacia necesaria dicha traslación" 32 .

Paralelamente se dirigió de forma directa a la reina Isabel $\mathrm{II}^{33}$, que por entonces tenía 14 años, explicándole aquella petición, la cual terminó aceptando con la emisión de la siguiente real orden: "La Reyna conformandose con el parecer de V.S. Se ha dignado mandar que la celebre escultura que ecsiste en ese Museo provincial conocida con el nombre del cristo de Montañez, se coloque de nuevo, con calidad de deposito en esa Santa Yglesia Catedral. De Real Orden lo comunico á V.S. para su inteligencia y demas efectos. Dios que á V.S. m.a. Madrid 28 de Marzo de 1845 = Pidal = Sor. Gefe politico de Sevilla" ${ }^{4}$.

La confirmación oficial por parte de la Comisión de Monumentos se hizo en la sesión del 11 de abril de 1845, en la que se remitió la real orden al deán de la

${ }^{31}$ AMADOR DE LOS RÍOS, José: Sevilla pintoresca o Descripción de sus más célebres monumentos artísticos. Sevilla, 1844, pp. 390-391.

32 A.C.M.S., Libro de actas I, 5-3-1845.

${ }_{33}$ A.C.M.S., Edificios y Monumentos de Sevilla, leg. Sevilla A-F.

34 A.C.M.S., Antecedentes del Museo Provincial de Pinturas y Esculturas de Sevilla, expediente $\mathrm{n}^{\mathrm{o}} 2$. Oficio recibido el 5 de abril por la Comisión de Monumentos por conducto del Jefe Político. 
catedral de Sevilla ${ }^{35}$. Como supervisor del envío del Crucificado, se señaló al conserje del Museo, haciendo especial hincapié en que fuera "trasladada con calidad de deposito á la $S^{a}$ Yglesia Catedral al lugar que antes ocupaba" (Figuras 4 y 5 ) $^{36}$.

En toda la documentación del proceso siempre queda claro que el carácter del traslado era en calidad de depósito, por lo que en ningún momento se renuncia por parte del Museo a la propiedad del Cristo de la Clemencia.

Aquello fue tratado en el cabildo de la catedral celebrado el día 6 de mayo de 1845, decidiendo que Joaquín Pérez sería la persona encargada de dirigir la recogida de la escultura ${ }^{37}$. La Comisión de Monumentos respondió marcando como día de la recogida el sábado 31 de mayo de 1845 a la una del mediodía ${ }^{38}$, momento en que se hallaría en el Museo un vocal de la comisión junto al secretario a la espera de recibir y recoger el resguardo de entrega, que fue el que sigue: "He recivido del Conserge del Museo Provincial de esta Ciudad la efigie titulada el Cristo de Montañes en estado perfecto de conservacion; y para resguardo del mismo firmo el presente en Sevilla a 31 de Mayo de 1845. Como encargado del Yltmo Cab. Ecco. Joaquin Perez" (Figura 6) ${ }^{39}$.

Tal y como se puede comprobar, López Cepero puso bastante interés en el traslado del Cristo de la Clemencia a la catedral. ¿Hasta qué punto es lógico que el vicepresidente de una institución museística quisiera prescindir de una obra maestra de tal calibre? De hecho, no puede achacársele a una cuestión de criterios artísticos o de preferencias de la pintura sobre la escultura ya que, por el contrario, largo y tedioso fue el proceso para intentar salvar la sillería de coro de la Cartuja o los grandes esfuerzos por proteger al San Jerónimo de Torrigiano.

Estudiando las razones a las que alude, Cepero dice que el Museo no es un sitio acorde para el lucimiento de aquella obra, algo que resulta contradictorio al observar las enormes dimensiones del edificio de la Merced. De hecho, el gran salón correspondiente a la antigua iglesia podría marcarse en el momento como el espacio perfecto para aquello, sobre todo encontrándose en continuas obras y remodelación de los espacios del antiguo convento.

Quizás la respuesta pueda venir solo en parte en la siguiente frase: "á mas de que la veneración que en Sevilla se le tributa hacía necesaria dicha traslación"40. Y se remarca "en parte" porque es muy posible que confluyan varios intereses en este asunto. Partiendo del estrictamente religioso, se trata de una talla que levantaba un enorme fervor en la ciudad, y se llega a la consideración de que el Museo no es un entorno propicio para la devoción. Esto de forma aislada atendiendo

${ }^{35}$ A.C.M.S., Libro de actas I, 11-4-1845.

${ }^{36}$ A.C.M.S., Antecedentes del Museo Provincial de Pinturas y Esculturas de Sevilla, expediente $\mathrm{n}^{\circ}$ 2. Oficio al Sr. Conserje del museo provincial de Sevilla, 11-4-1845.

${ }^{37}$ Ibidem, oficio 26-5-1845.

${ }^{38}$ Ibid., nota sin fechar.

${ }^{39}$ Ibid., 31-5-1845.

40 A.C.M.S., Libro de actas I, 5-3-1845. 
solamente al Crucificado queda bastante justificado, pero solo hay que prestar atención al resto de la colección del Museo, la cual estaba compuesta casi exclusivamente de imágenes religiosas, de las que habría más de una que también arrastrase devoción popular.

Habría que añadir al aspecto religioso, la posición que desempeñaba en el cabildo de la catedral de Sevilla. Manuel López Cepero fue nombrado canónigo de la catedral de Sevilla por real decreto de 14 de noviembre de 1835 y deán por real decreto de 12 de abril de $1844^{41}$. La estrecha relación que desempeñaba Cepero con el cabildo sevillano desde hacía bastante tiempo pudo ser la que hizo que se decantase por preferir a la catedral como el lugar donde debía estar ubicado el Crucificado de Montañés. A lo largo de su vida no solo fue un hombre de fe, sino también un gran amante del arte, por lo que era totalmente consciente del peso de su decisión de trasladar aquella obra a la catedral. ¿Pudo haber sido beneficioso para su status en el plano religioso? ¿O se trató de un juicio puro emitido sin intereses? Todo esto ya entra en el plano de la pura especulación. Lo que sí está claro es el gran interés que la talla de Montañés despertaba en López Cepero, relación que seguro se remontaba a sus años de reclusión en la Cartuja tras la invasión francesa ${ }^{42}$.

Al llegar a la Catedral desde su "cuarto del Cristo" en el Museo, se le ubicó en la sacristía de los Cálices, "en el nicho principal frente a la puerta" ${ }^{43}$, de cuya estancia adquirió el sobrenombre tradicional del "Cristo de los Cálices". Es posible que ya hubiese presidido aquel espacio en los años anteriores a la habilitación de la Merced. El hecho es que, a día de hoy, el magnífico Crucificado de Martínez Montañés sigue con calidad de depósito en la catedral para el deleite de fieles y visitantes, alzándose como la mejor obra atesorada dentro del templo sevillano.

Muchos visitantes continuaron llegando al Museo con intención de contemplar el Crucificado y reaccionando con extrañeza al saber que había sido trasladado a la catedral a pesar de pertenecer a aquella institución: "Se conoce ademas del mismo autor un Cristo, escultura admirable que, aun cuando pertenece al Museo, se halla, como en calidad de depósito, en la iglesia catedral de esta ciudad; depósito estraño, pues juzgamos que nunca debió haberse estraido del sitio que ocupara en aquel local"44.

Fecha de recepción: 30 de septiembre de 2016

Fecha de aceptación: 9 de febrero de 2017

${ }^{41}$ ROS GONZÁLEZ, Francisco S.: "Manuel López Cepero y la reforma de la iglesia de la Universidad de Sevilla", Laboratorio de Arte, 19, 2006, p. 425.

42 PABÓN, J.: "Del Deán López Cepero...", op. cit., p. 463.

${ }^{43}$ GESTOSO Y PÉREZ, J.: Guía artística de Sevilla: historia y descripción de sus principales monumentos religiosos y civiles, y noticia de las preciosidades artístico-arqueológicas que en ellos se conservan... Sevilla, 1884, p. 108.

44 JIMÉnEZ, M.: "Una Visita al Museo de Pinturas de Sevilla", Semanario Pintoresco Español, T. II, nº 48, 28-11-1847, p. 379. 


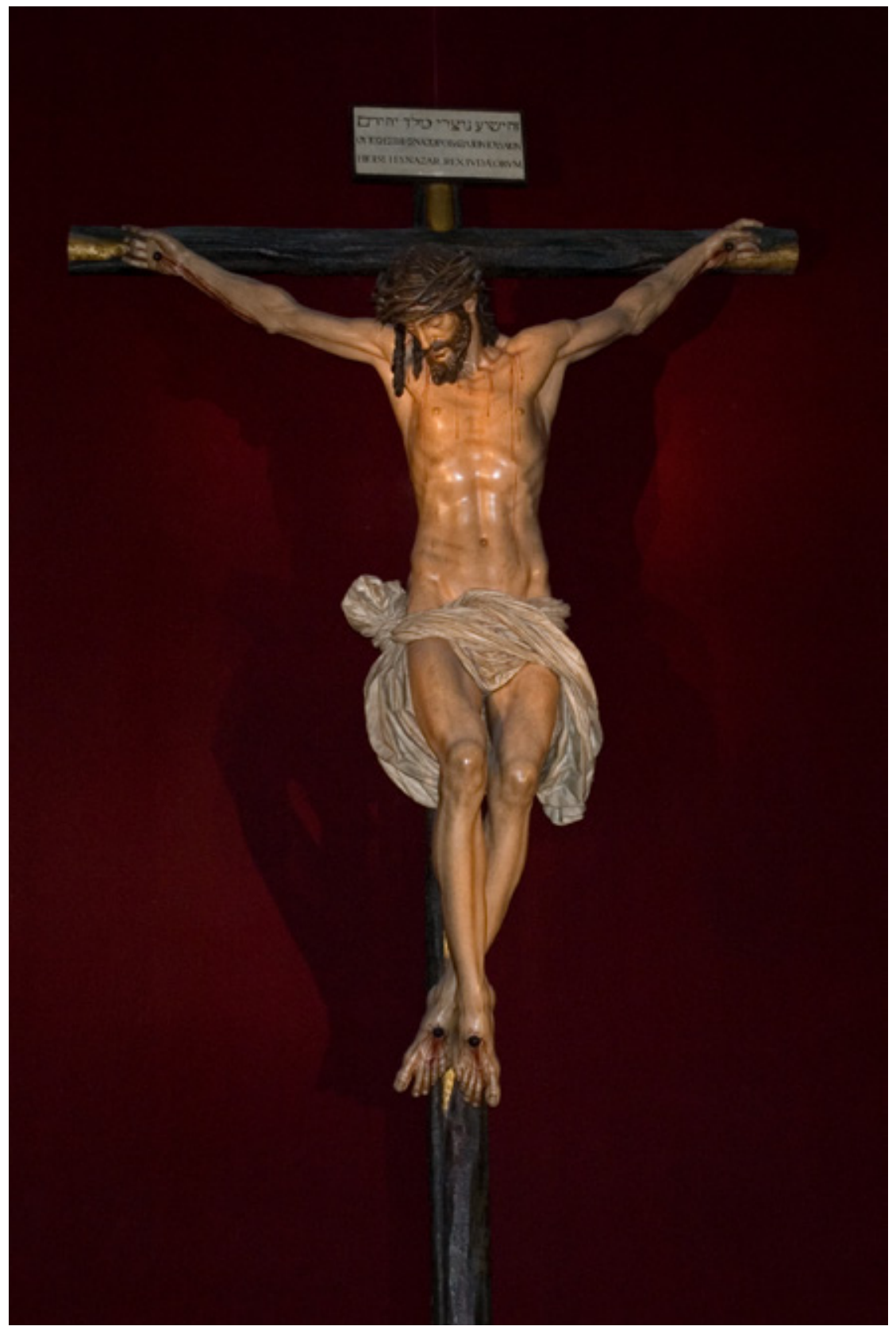

Figura 1. Juan Martínez Montañés, Cristo de la Clemencia, 1603-1606, catedral de Sevilla.

LABORATORIO DE ARTE 29 (2017), pp. 243-258, ISSN 1130-5762 e-ISSN 2253-8305 - DOI http://dx.doi.org/10.12795/LA.2017.i29.12 


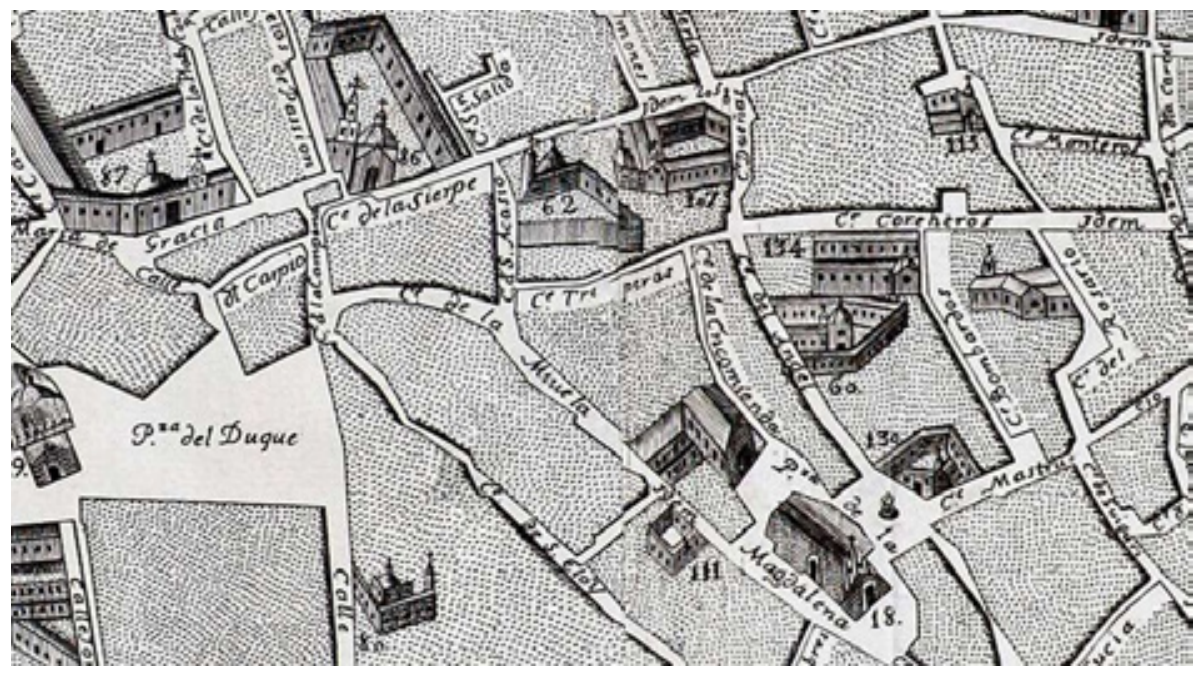

Figura 2. Plano de Sevilla, 1771, detalle de la calle Colcheros, enclave del hospital del Espíritu Santo, depósito de bienes desamortizados.

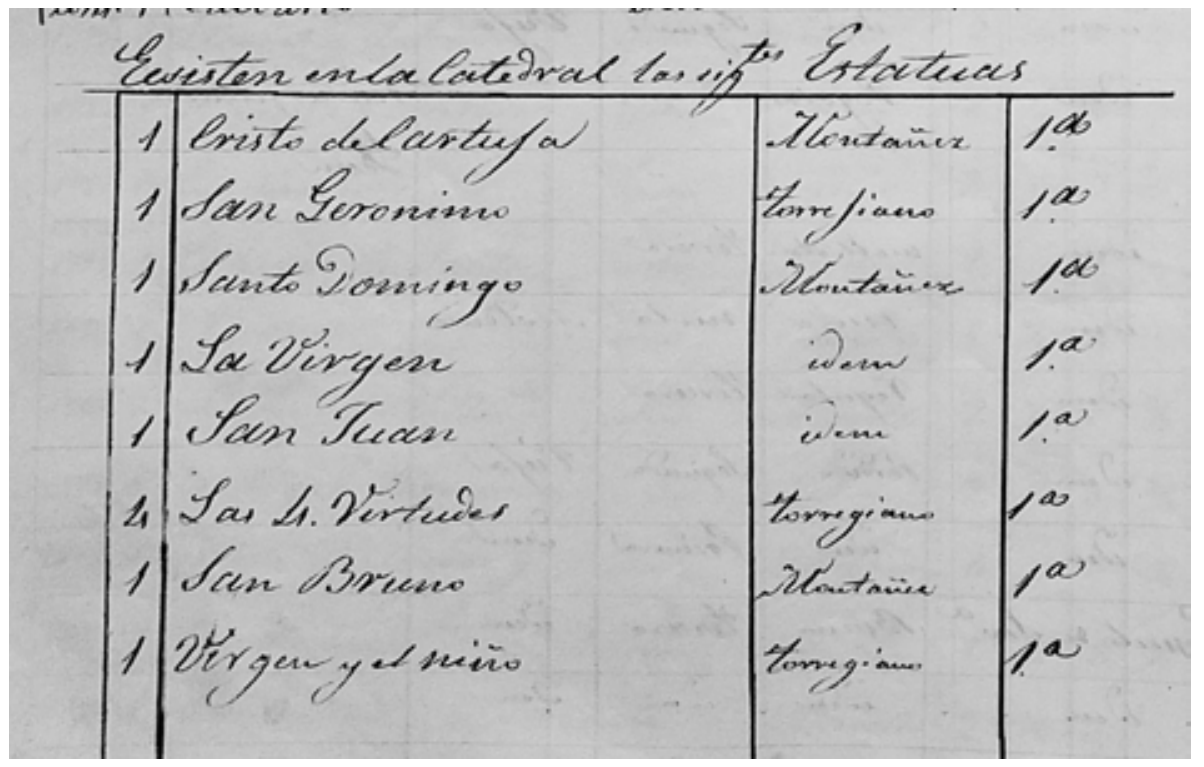

Figura 3. Detalle del listado de esculturas, incluido en el inventario del Museo del 31-12-1840. Archivo de la Real Academia de Bellas Artes de Santa Isabel de Hungría. 


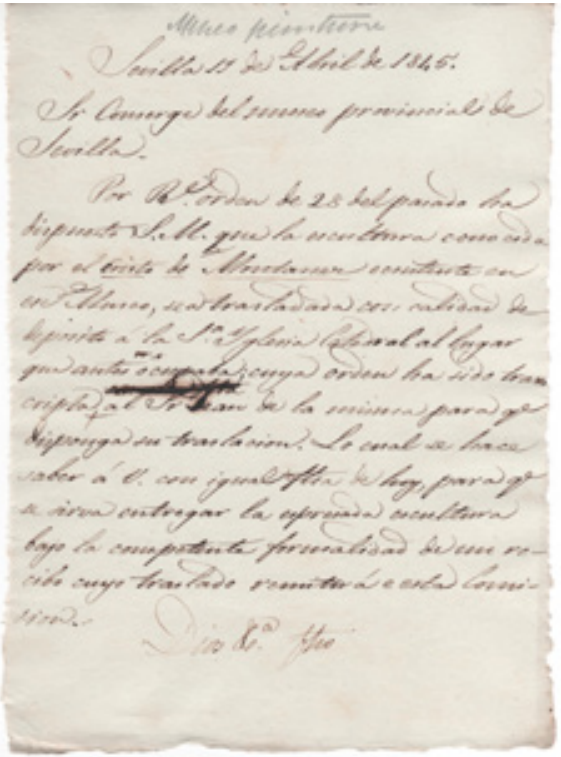

Figura 4. Documento autorizando el depósito del Cristo de la Clemencia en la catedral, 11-4-1845. Archivo de la Real Academia de Bellas Artes de Santa Isabel de Hungría.

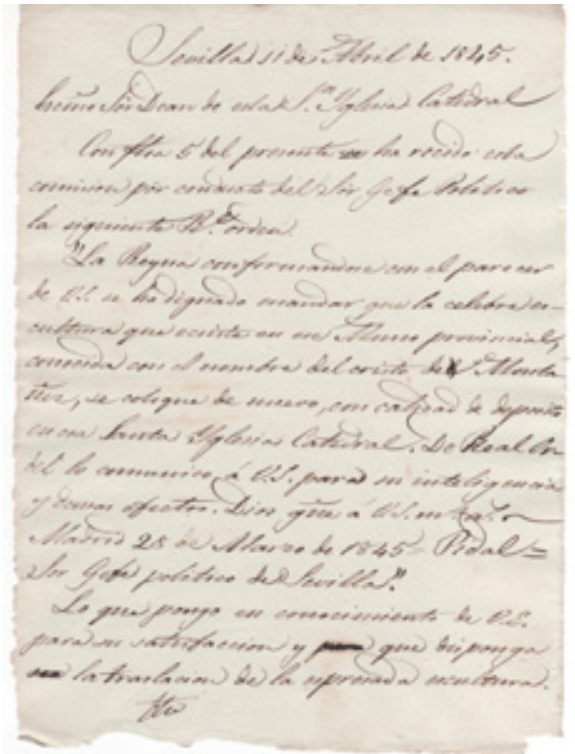

Figura 5. Documento autorizando el depósito del Cristo de la Clemencia en la catedral, 11-4-1845. Archivo de la Real Academia de Bellas Artes de Santa Isabel de Hungría.

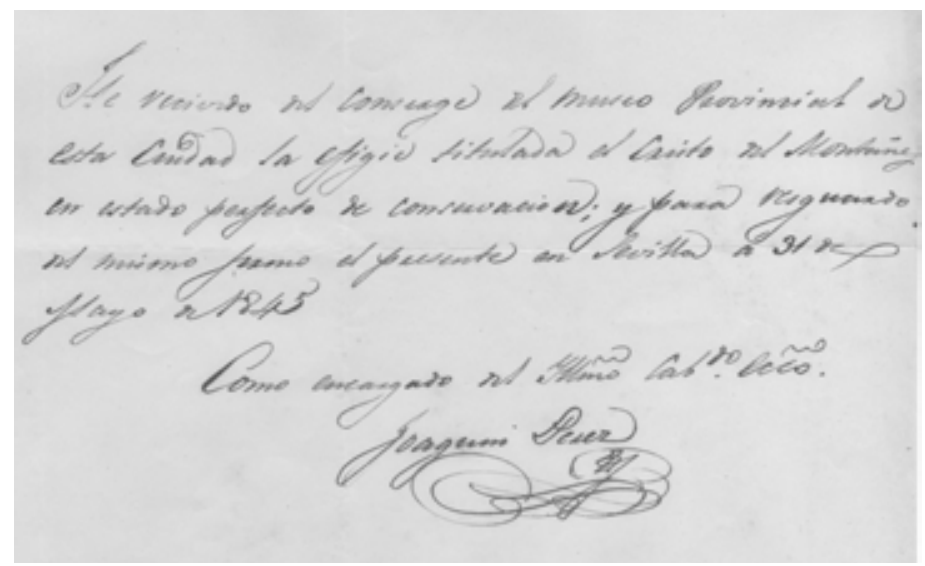

Figura 6. Resguardo de recogida del Cristo de la Clemencia, 31-5-1845. Archivo de la Real Academia de Bellas Artes de Santa Isabel de Hungría. 